\title{
The role of radiotherapy in the management of POEMS syndrome
}

\author{
Yang-Gun Suh', Young-Suk Kim, Chang-Ok Suh', Yu Ri Kim², June-Won Cheong², Jin Seok Kim² and Jaeho Cho ${ }^{1 *}$
}

\begin{abstract}
Background: POEMS syndrome is a paraneoplastic syndrome caused by an underlying plasma cell proliferative disease. In this study, we examined the treatment outcomes and role of radiotherapy in the management of POEMS syndrome.

Methods: In total, 33 patients diagnosed with POEMS syndrome were analyzed. These patients presented with osteosclerotic myeloma (OSM, $n=13)$, Castleman's disease $(C D, n=4)$, OSM with CD $(n=10)$, and vascular endothelial growth factor elevation without gross lesions (VEGFe, $n=6$ ), respectively. The patients were treated by radiotherapy alone $(n=4)$, chemotherapy alone $(n=16)$, or a combination thereof $(n=9)$.
\end{abstract}

Results: The clinical response rates of radiotherapy, chemotherapy, and radiotherapy plus chemotherapy were $75 \%$, $69 \%$, and $89 \%$, respectively. In addition, the hematologic response rates were $50 \%, 69 \%$, and $71 \%$, respectively. Among the six patients with limited multiple lesions who underwent radiotherapy, the clinical symptoms were improved in five patients after radiotherapy. The median progression-free survival (PFS) was 51 months, and the median overall survival (OS) was 65 months. In univariate analysis, the administration of chemotherapy was significantly associated with better PFS $(p=0.007)$ and OS $(p=0.020)$. In contrast, underlying VEGFe was a significant factor worsening PFS $(p=0.035)$ and OS $(p=0.008)$.

Conclusions: Radiotherapy produces a reliable clinical response and is effective in improving POEMS-associated symptoms that are refractory to chemotherapy in selected patients with clustered or limited multiple lesions that can be covered by single radiation field.

Keywords: Chemotherapy, Osteosclerotic myeloma, Castleman's disease, Monoclonal gammopathy, Polyneuropathy

\section{Background}

The term POEMS is derived from the primary features of the disease: polyneuropathy, organomegaly, endocrinopathy, M protein, and skin changes [1]. POEMS syndrome is a paraneoplastic syndrome caused by an underlying plasma cell disorders such as osteosclerotic myeloma (OSM) or Castleman's disease (CD) [2,3]. Polyneuropathy is a typical symptom of this syndrome, and can be fatal if it is not improved with treatments [4-6]. Other important clinical features, which are not included in the POEMS acronym, include papilledema, thrombocytosis/erythrocytosis, elevated vascular endothelial growth factor (VEGF) levels, and extravascular volume overload such as peripheral edema, ascites,

\footnotetext{
* Correspondence: jjhmd@yuhs.ac

${ }^{1}$ Department of Radiation Oncology, Yonsei University College of Medicine, 50-1 Yonsei-ro, Seodaemun-gu, Seoul 120-752, South Korea

Full list of author information is available at the end of the article
}

pleural effusion, and pericardial effusion [6-9]. Since there is no single diagnostic test for the diagnosis of POEMS syndrome, the diagnosis is typically based on the presence of polyneuropathy associated with monoclonal plasma cell disorders presenting with the distinct symptoms described above. Currently, the Mayo Clinic POEMS diagnostic criteria are generally accepted and widely used $[3,6,10]$.

Previous studies have shown that radiotherapy and chemotherapy are effective treatments for solitary and multiple lesions, respectively [10-13]. Sometimes, surgery can be an option for patients with cranial vault plasmacytoma [14]. However, the role of radiotherapy in patients with multiple lesions remains unclear, and the treatment outcomes vary according to the underlying plasma cell disorders [15].

( Biomed Central

(c) 2014 Suh et al.; licensee BioMed Central Ltd. This is an Open Access article distributed under the terms of the Creative Commons Attribution License (http://creativecommons.org/icenses/by/4.0), which permits unrestricted use, distribution, and reproduction in any medium, provided the original work is properly credited. The Creative Commons Public Domain Dedication waiver (http://creativecommons.org/publicdomain/zero/1.0/) applies to the data made available in this article, unless otherwise stated. 
In the current study, we analyzed the effects of various treatments, including radiotherapy, chemotherapy, or combined treatment on the symptoms and disease control in patients with POEMS syndrome.

\section{Methods}

\section{Patients}

We retrospectively reviewed the medical records of 33 patients who met diagnostic criteria for POEMS syndrome, as proposed by the Mayo clinic [7] and treated at the Yonsei University Health System in Seoul, Korea, in the period between March of 2000 and February of 2013. Patients were diagnosed with POEMS syndrome if they met the two mandatory major criteria (polyneuropathy and monoclonal plasma cell-proliferative disorder), at least one of the other major criteria (CD, sclerotic bone lesion, and VEGF elevation), and at least one of the minor criteria (organomegaly, extravascular volume overload, endocrinopathy, skin changes, papilledema, and thrombocytosis/polycythemia). Plasma cell-proliferative

Table 1 Patient clinicodemographic characteristics and laboratory findings

\begin{tabular}{|c|c|c|c|c|}
\hline \multirow[t]{2}{*}{ Characteristic } & \multirow{2}{*}{$\begin{array}{l}\text { All }(n=33) \\
\text { No. of patients (\%) }\end{array}$} & \multirow{2}{*}{$\begin{array}{l}\text { RT }(n=13) \\
\text { No. of patients (\%) }\end{array}$} & \multicolumn{2}{|l|}{ Non-RT $(n=20)$} \\
\hline & & & No. of patients (\%) & $p$ value $^{*}$ \\
\hline Median age, year (range) & $45(25-68)$ & $51(25-68)$ & $45(28-63)$ & 0.592 \\
\hline \multicolumn{5}{|l|}{ Gender } \\
\hline Male & $24(73)$ & $12(92)$ & $12(60)$ & \multirow[t]{2}{*}{0.056} \\
\hline Female & $9(27)$ & $1(8)$ & $8(40)$ & \\
\hline \multicolumn{5}{|l|}{ ECOG performance status } \\
\hline 1 & $6(18)$ & $2(15)$ & $4(20)$ & \multirow[t]{3}{*}{0.451} \\
\hline 2 & $11(33)$ & $6(46)$ & $5(25)$ & \\
\hline 3 & $16(48)$ & $5(39)$ & $11(55)$ & \\
\hline \multicolumn{5}{|l|}{ Number of POEMS features } \\
\hline$\leq 7$ features & $19(58)$ & $7(54)$ & $12(60)$ & \multirow[t]{2}{*}{1.000} \\
\hline$>7$ features & $14(42)$ & $6(46)$ & $8(40)$ & \\
\hline \multicolumn{5}{|l|}{ Type of M-protein } \\
\hline $\lg G$ & $17(52)$ & $8(62)$ & $9(45)$ & \multirow[t]{3}{*}{0.305} \\
\hline $\lg A$ & $13(39)$ & $5(38)$ & $8(40)$ & \\
\hline $\lg G$ and $\lg A$ & $3(9)$ & $0(0)$ & $3(15)$ & \\
\hline \multicolumn{5}{|l|}{ Type of plasma cell-proliferative disorder } \\
\hline OSM & $13(39)$ & $8(62)$ & $5(25)$ & 0.067 \\
\hline$C D$ & $4(12)$ & $0(0)$ & $4(20)$ & 0.136 \\
\hline $\mathrm{OSM}+\mathrm{CD}$ & $10(30)$ & $5(38)$ & $5(25)$ & 0.461 \\
\hline VEGF elevation without gross lesion & $6(18)$ & $0(0)$ & $6(30)$ & 0.060 \\
\hline \multicolumn{5}{|l|}{ Plasma cell component in bone marrow } \\
\hline$\leq 5 \%$ & $20(61)$ & $8(62)$ & $12(60)$ & \multirow[t]{2}{*}{1.000} \\
\hline$>5 \%$ & $13(39)$ & $5(38)$ & $8(40)$ & \\
\hline \multicolumn{5}{|c|}{ Abnormal clonal plasma cells in bone marrow } \\
\hline Absent & $28(85)$ & $13(100)$ & $15(75)$ & \multirow[t]{2}{*}{0.131} \\
\hline Present & $5(15)$ & $0(0)$ & $5(25)$ & \\
\hline \multicolumn{5}{|l|}{ Laboratory findings } \\
\hline $\mathrm{ESR}>20 \mathrm{~mm} / \mathrm{h}$ & $16(48)$ & $5(38)$ & $11(55)$ & 1.000 \\
\hline Hemoglobin $<11 \mathrm{~g} / \mathrm{dL}$ & $2(6)$ & $0(0)$ & $2(10)$ & 0.508 \\
\hline Hemoglobin $>16 \mathrm{~g} / \mathrm{dL}$ & $5(15)$ & $4(31)$ & $1(5)$ & 0.066 \\
\hline Platelets $>450 \times 10^{3} / \mu \mathrm{L}$ & $11(33)$ & $2(15)$ & $9(45)$ & 0.128 \\
\hline Creatinine clearance $<60 \mathrm{~mL} / \mathrm{min}$ & $5(15)$ & $0(0)$ & $5(25)$ & 0.131 \\
\hline
\end{tabular}

RT, radiotherapy; ECOG, Eastern Cooperative Oncology Group; Ig, immunoglobulin; OSM, osteosclerotic myeloma; CD, Castleman's disease; VEGF, vascular endothelial growth factor; ESR, erythrocyte sedimentation rate.

*The $p$ value was calculated by the Pearson's Chi-squared test between RT and non-RT. 
disorders were classified into four groups: OSM, CD, OSM with CD, and VEGF elevation without gross lesions. All patients underwent pretreatment evaluation including a complete blood cell count (CBC), blood chemistry analysis, serum and urine electrophoresis and immunofixation to detect M-protein, whole body bone scan (WBBS), positron emission tomography/computed tomography, and bone marrow biopsies from the bilateral iliac bones; in patients treated after 2007, the serum VEGF levels were measured. To identify the gross aggregation of plasma cells in the bone marrow, immunohistochemistry for syndecan-1 (CD138) was performed.
The study was approved by the Institutional Review Board of the Yonsei University Health System.

\section{Follow-up}

The treatment responses were evaluated on the basis of several outcomes, including subjective symptom improvements reported by the patients or treating physicians, and physical examination findings. Furthermore, a nerve conduction velocity test, serum immunoglobulin (Ig)A/G/M, lambda/kappa chain, and imaging studies were also performed to evaluate the treatment responses. Clinical responses were evaluated by assessing improvements in

Table 2 POEMS features of the study patients

\begin{tabular}{|c|c|c|c|c|}
\hline \multirow[t]{2}{*}{ Characteristic } & All $(n=33)$ & $\mathrm{RT}(n=13)$ & Non-RT $(n=20)$ & \multirow{2}{*}{$\begin{array}{l}p \\
\text { value }\end{array}$} \\
\hline & No. of patients (\%) & No. of patients (\%) & No. of patients (\%) & \\
\hline \multicolumn{5}{|l|}{ Polyneuropathy } \\
\hline Peripheral neuropathy & $33(100)$ & $13(100)$ & $20(100)$ & $\mathrm{N} / \mathrm{A}$ \\
\hline CSF protein $>50 \mathrm{mg} / \mathrm{dL}$ & 18/20 (90) & $5 / 5(100)$ & $13 / 15(87)$ & 1.00 \\
\hline \multicolumn{5}{|l|}{ Organomegaly } \\
\hline Hepatomegaly & $16(48)$ & $6(46)$ & $10(50)$ & 1.000 \\
\hline Splenomegaly & $18(55)$ & $7(54)$ & $11(55)$ & 0.614 \\
\hline Lymphadenopathy & $15(45)$ & $5(38)$ & $10(50)$ & 0.722 \\
\hline \multicolumn{5}{|l|}{ Endocrinopathy } \\
\hline Diabetes mellitus & $6(18)$ & $3(23)$ & $3(15)$ & 0.659 \\
\hline Hypothyroidism & $15(45)$ & $3(23)$ & $12(60)$ & 0.072 \\
\hline Gonadal axis abnormality & $10(30)$ & $3(23)$ & $7(35)$ & 0.701 \\
\hline Adrenal axis abnormality & $8(24)$ & $5(38)$ & $3(15)$ & 0.213 \\
\hline Hyperparathyroidism & $0(0)$ & $0(0)$ & $0(0)$ & N/A \\
\hline \multicolumn{5}{|l|}{ Skin changes } \\
\hline Hyper-pigmentation & $25(76)$ & $11(85)$ & $14(70)$ & 0.431 \\
\hline Acrocyanosis and plethora & $1(3)$ & $0(0)$ & $1(5)$ & 1.000 \\
\hline Hemangioma/telangiectasia & $0(0)$ & $0(0)$ & $0(0)$ & N/A \\
\hline Hypertrichosis & $16(48)$ & $6(46)$ & $10(50)$ & 1.000 \\
\hline \multicolumn{5}{|l|}{ Extravascular volume overload } \\
\hline Peripheral edema & $19(58)$ & $6(46)$ & $13(65)$ & 0.472 \\
\hline Ascites & $12(36)$ & $1(8)$ & $11(55)$ & 0.009 \\
\hline Pleural effusion & $13(39)$ & $1(8)$ & $12(60)$ & 0.004 \\
\hline Pericardial effusion & $7(21)$ & $0(0)$ & $7(35)$ & 0.027 \\
\hline \multicolumn{5}{|l|}{ Types of bone lesion } \\
\hline Osteolytic & $4(12)$ & $2(15)$ & $2(10)$ & 0.488 \\
\hline Osteosclerotic & $14(42)$ & $7(54)$ & $7(35)$ & \\
\hline Mixed & $5(15)$ & $4(31)$ & $1(5)$ & \\
\hline \multicolumn{5}{|l|}{ No. of bone lesion } \\
\hline None & $10(30)$ & $0(0)$ & $10(50)$ & 0.008 \\
\hline Solitary & $11(33)$ & $7(54)$ & $4(20)$ & \\
\hline Multiple & $12(36)$ & $6(46)$ & $6(30)$ & \\
\hline
\end{tabular}

RT, radiotherapy; CSF, cerebrospinal fluid; N/A, not applicable.

*The $p$ value was calculated by the Pearson's Chi-squared test between RT and non-RT. 
symptoms associated with POEMS syndrome, such as polyneuropathy, skin changes, pulmonary edema, and extravascular volume overload. Clinical response was categorized as improved, mixed, stable, or progressed according to previous study [12], and only the patients who experienced clinical symptom improvement were considered as responder. Hematologic responses were defined using the criteria from a previous study [11]: complete hematologic response $\left(\mathrm{CR}_{\mathrm{H}}\right)$, no abnormal plasma cell aggregation in the bone marrow and negative immunofixation in the serum and urine; very good partial response $\left(\mathrm{VGPR}_{\mathrm{H}}\right)$, a $90 \%$ reduction in the M-protein levels or positive immunofixation, as long as M-protein level was at least $0.5 \mathrm{~g} / \mathrm{dL}$ at baseline; and partial hematologic response $\left(\mathrm{PR}_{\mathrm{H}}\right)$, a $50 \%$ reduction in serum M-protein levels. Other cases were defined as no hematologic response $\left(\mathrm{NR}_{\mathrm{H}}\right)$. Follow-up monitoring included $\mathrm{CBC}$, blood chemistry analyses, serum and urine assays to detect M-protein, and imaging studies of the treated areas. Progression was defined as any event as follows; increase in the M-component in the serum or urine, aggravation of symptoms associated with POEMS syndromes, or progression of disease observed upon imaging studies.

\section{Statistical analysis}

Progression-free survival (PFS) and overall survival (OS) were quantified from the date of diagnosis to the event of interest. Statistical analyses were conducted using SPSS version 20 (SPSS Inc., Chicago, IL). A $p$ value $<0.05$ was considered statistically significant. Differences in clinical features and response rates between patient groups were analyzed using the Pearson's Chi-squared test. Patient survival was evaluated using Kaplan-Meier survival curves, and the log-rank test was used to compare survival rates between groups. Prognostic factors for survival were analyzed by univariate analyses using the log-rank test.

\section{Results}

\section{Patient characteristics}

The clinical and laboratory characteristics of the patients at the time of diagnosis are summarized in Table 1. All patients presented with a sensorimotor polyneuropathy in nerve conduction test. Sixteen (48\%) patients had a poor performance status of Eastern Cooperative Oncology Group performance score (3), owing to the presence of peripheral polyneuropathy. All patients presented with more than four features included in the Mayo Clinic diagnostic criteria, and $42 \%$ of patients presented with more than seven features. Thirty (91\%), one (3\%), and two (6\%) patients presented with lambda, kappa, and both light chains, respectively. The median frequency of plasma cells in the bone marrow was $3 \%$ (range, $0-18 \%$ ).

The features of POEMS syndrome according to the administration of radiotherapy are summarized in Table 2 .
Peripheral polyneuropathy, one of the major diagnostic criteria, was observed in all patients. All patients presented with polyneuropathy in the lower extremities, and $10 \mathrm{pa}-$ tients also had polyneuropathy in the upper extremities. For the 10 patients with polyneuropathy in both the upper and lower extremities, the symptoms had presented in the lower extremities first. Elevated protein levels in the cerebrospinal fluid were observed in 18 patients among 20 patients with available data (90\%). The frequencies of extravascular volume overload including ascites $(p=0.009)$, and pleural effusion $(p=0.004)$ and pericardial effusion $(p=0.027)$ were significantly lower in patients who underwent radiotherapy. The frequency of patients presenting bone lesions was significantly higher in patients treated with radiotherapy compared to all other patients (100\% versus $50 \%, p=0.008)$.

Radiotherapy was administered to 13 patients (39\%) presenting with OSM with or without $\mathrm{CD}$, and non of these patients presented with abnormal clonal plasma cells in the bone marrow. Almost patients $(\mathrm{n}=10)$ treated with radiation doses of $40 \mathrm{~Gy}$ or more. Twenty-five patients (76\%) were treated with chemotherapy. Four patients did not undergo definitive radiotherapy or chemotherapy due to low performance status or patients' refusal; three of these patients were instead treated with prednisolone or dexamethasone alone, while one patient received prednisolone and intravenous immunoglobulin. Nine patients received both radiotherapy and chemotherapy. Detailed treatment features are summarized in Table 3.

Table 3 Treatments

\begin{tabular}{|c|c|c|c|}
\hline Variable & $\begin{array}{l}\text { No. of } \\
\text { case (\%) }\end{array}$ & Median & Range \\
\hline Radiotherapy & $13(100)$ & & \\
\hline \multicolumn{4}{|l|}{ Irradiated site } \\
\hline Spine & $6(46)$ & $\mathrm{N} / \mathrm{A}$ & $\mathrm{N} / \mathrm{A}$ \\
\hline Pelvic bone & $5(38)$ & $\mathrm{N} / \mathrm{A}$ & $\mathrm{N} / \mathrm{A}$ \\
\hline Lymph nodes & $2(15)$ & $\mathrm{N} / \mathrm{A}$ & N/A \\
\hline \multicolumn{4}{|l|}{ No. of irradiated bone lesions } \\
\hline Single & $7(54)$ & 1 & 1 \\
\hline Multiple & $6(46)$ & 4 & $2-6$ \\
\hline Total dose, Gy & $13(100)$ & 45 & $30-50$ \\
\hline Fraction size, Gy & $13(100)$ & 2 & $1.8-3$ \\
\hline Chemotherapy & $25(100)$ & & \\
\hline Melphalan and prednisolone & $4(16)$ & $\mathrm{N} / \mathrm{A}$ & $\mathrm{N} / \mathrm{A}$ \\
\hline $\begin{array}{l}\text { Vincristine, doxorubicin, and } \\
\text { dexamethasone }\end{array}$ & $2(8)$ & $\mathrm{N} / \mathrm{A}$ & $\mathrm{N} / \mathrm{A}$ \\
\hline High-dose chemotherapy with APBSCT & $15(60)$ & $\mathrm{N} / \mathrm{A}$ & $\mathrm{N} / \mathrm{A}$ \\
\hline Others & $4(16)$ & $\mathrm{N} / \mathrm{A}$ & $\mathrm{N} / \mathrm{A}$ \\
\hline
\end{tabular}

N/A, non applicable; APBSCT, autologous peripheral blood stem cell transplantation. 


\section{Treatment responses}

The various treatments and the responses according to the underlying disease are summarized in Figure 1. Among the 23 patients presenting with OSM (with or without $\mathrm{CD}$ ), six and 14 patients were initially treated with radiotherapy and chemotherapy, respectively. The proportions of patients showing improved clinical symptoms after the initial treatment were $67 \%$ and $50 \%$ in the radiotherapy and chemotherapy groups, respectively. Out of the 14 patients who initially received chemotherapy, seven patients subsequently received radiotherapy due to poor clinical responses to chemotherapy alone.
Among these patients, three patients presented with a single bone lesion, whereas four patients had multiple bone lesions more than three. After salvage radiotherapy, six of these seven patients showed clinical response.

Six patients with multiple lesions underwent radiotherapy due to poor performance status deemed inadequate for chemotherapy $(n=2)$, and poor clinical symptom response after chemotherapy $(n=4)$. Out of these six patients, the clinical symptoms were improved in five patients after radiotherapy, although the serum $\mathrm{M}$-protein levels were reduced in only one patient by radiotherapy. The 10 patients with CD or VEGF elevation without gross lesions were

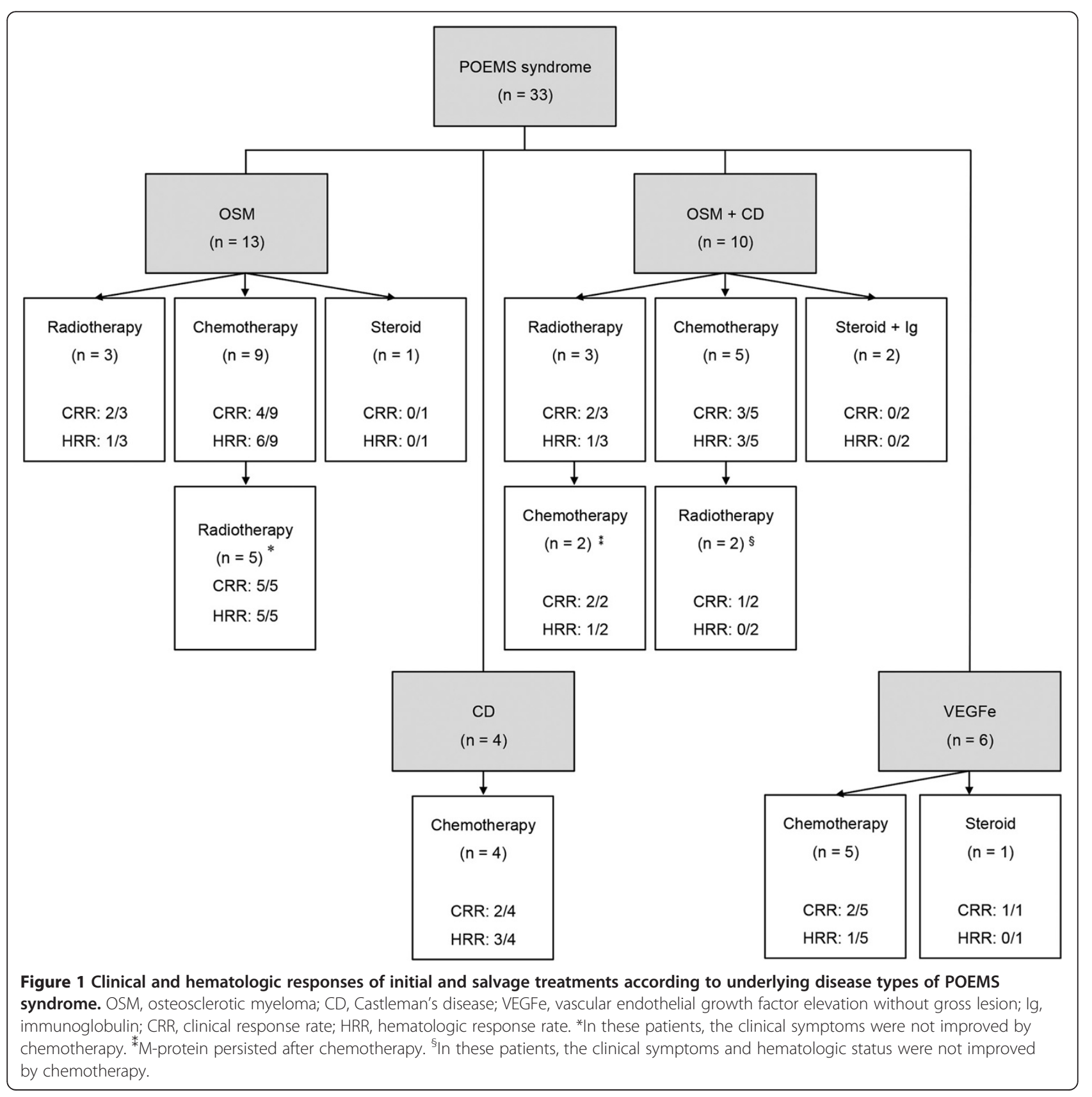


treated with chemotherapy $(n=9)$ or prednisolone and immunoglobulin $(\mathrm{n}=1)$.

Overall, 23 patients (70\%) showed improved clinical symptoms after treatments. The clinical response rates for the patients treated with radiotherapy alone, chemotherapy alone, and chemoradiotherapy were $75 \%, 69 \%$, and $89 \%$, respectively, and these were not statistically different according to the treatments $(p=0.528)$. In addition, two (50\%), 11 (69\%), and six patients (67\%) showed hematologic response after radiotherapy alone, chemotherapy alone, and chemoradiotherapy, respectively. No significant differences were observed between the treatment groups in hematologic response rate $(p=0.777)$. OSM patients with or without CD showed better clinical and hematologic responses compared with patients with $\mathrm{CD}$ only or VEGF elevation without gross lesions (Table 4).

\section{Survivals and prognostic factors}

The median follow-up was 40 months for the surviving patients. The median PFS for all patients was 51 months with the 5-year PFS rate being 43\% (Figure 2A). The 5-year PFS rate was better in patients treated with chemoradiotherapy (76\%) compared to patients treated with radiotherapy alone (33\%) or chemotherapy alone (28\%). However, this result was not statistically significant $(p=0.324)$. The median OS for all patients was 65 months, with the 5-year OS rate being 57\% (Figure 2B). The 5-year OS rate was worse in patients treated with radiotherapy alone $(25 \%)$ than patients treated with chemotherapy alone (68\%) or chemoradiotherapy (69\%). This result did not reach statistic significance $(p=0.094)$. During the follow-up period, 13 patients died, including two, five, four, one, and one from treatment-related causes after chemotherapy, renal failure, pneumonia, coronary artery occlusive disease, and cerebral hemorrhage after falling down, respectively.
The results of the univariate analyses for PFS and OS are shown in Table 5. In the univariate analyses, the use of chemotherapy was found to be a significant prognostic factor for PFS (3-year PFS, 71.5\% versus 17.5\%, $p=0.007$ ) and OS (3-year OS, $74.1 \%$ versus $18.2 \%, p=0.020$ ). Moreover, VEGF elevation without gross lesions was found to be associated with a worse PFS (3-year PFS, $25.0 \%$ versus $66 \%, p=0.035$ ) and OS (3-year OS, $16.7 \%$ versus $74.1 \%$, $p=0.008)$ compared with the other subtypes of POEMS syndrome.

\section{Discussion}

POEMS syndrome is a rare paraneoplastic syndrome resulting from underlying plasma cell proliferative diseases including OSM, CD, and VEGF elevation without gross lesion. Although a large case series of the disease was reported in the United States over a decade ago [6], the underlying pathogenesis and optimal treatment for POEMS syndrome remains unclear, partly due to the lack of randomized trials on the topic $[7,16]$. The results of the present study suggest that local radiotherapy could achieve durable clinical and hematologic responses in selected patients.

Osteosclerotic myeloma is characterized by osteosclerotic bone lesions caused by plasmacytoma or associated with POEMS syndrome. On the other hand, multiple myeloma is typically associated with osteolytic bone lesions [17], while bone lesions in cases of polyneuropathy are often osteosclerotic or mixed osteosclerotic and osteolytic $[5,6]$. Several studies have shown that OSM with a low burden of clonal plasma cells can be effectively treated with local radiotherapy [5,6,12,18-21]. Accordingly, in our study, we found that radiotherapy or radiotherapy plus chemotherapy produced a good clinical response of $89 \%$ and a hematologic response of $67 \%$. Although the optimal dose of radiation for OSM has not been thoroughly investigated, moderate doses of over 40 Gy may be

Table 4 Treatment responses according to treatment modality and type of plasma cell-proliferative disorder

\begin{tabular}{|c|c|c|c|c|c|c|c|c|c|}
\hline \multirow[t]{3}{*}{ Feature } & \multirow{3}{*}{$\begin{array}{l}\text { No. of } \\
\text { Pts, }\end{array}$} & \multirow{2}{*}{\multicolumn{4}{|c|}{$\begin{array}{l}\text { Clinical response } \\
\text { No. of patients (\%) }\end{array}$}} & \multirow{2}{*}{\multicolumn{4}{|c|}{$\begin{array}{l}\text { Hematologic response } \\
\text { No. of patients (\%) }\end{array}$}} \\
\hline & & & & & & & & & \\
\hline & & Improved & Mixed & Stable & Progression & $\mathrm{CR}_{\mathrm{H}}$ & $\mathrm{VGPR}_{\mathrm{H}}$ & $\mathrm{PR}_{\mathrm{H}}$ & $\mathrm{NR}_{\mathrm{H}}$ \\
\hline RT & 4 & $3(75)$ & $0(0)$ & $1(25)$ & $0(0)$ & $1(25)$ & $1(25)$ & $0(0)$ & $2(50)$ \\
\hline $\mathrm{CHT}$ & 16 & $11(69)$ & $1(6)$ & $2(13)$ & $2(13)$ & $5(31)$ & $2(13)$ & $4(25)$ & $5(31)$ \\
\hline $\mathrm{RT}+\mathrm{CHT}$ & 9 & $8(89)$ & $0(0)$ & $0(0)$ & $1(11)$ & $4(44)$ & $1(11)$ & $1(11)$ & $3(33)$ \\
\hline Steroid or lg & 4 & $1(25)$ & $1(25)$ & $1(25)$ & $1(25)$ & $0(0)$ & $0(0)$ & $0(0)$ & $4(100)$ \\
\hline OSM & 13 & $11(84)$ & $0(0)$ & $1(8)$ & $1(8)$ & $6(46)$ & $1(8)$ & $3(23)$ & $3(23)$ \\
\hline$C D$ & 4 & $2(50)$ & $0(0)$ & $1(25)$ & $1(25)$ & $0(0)$ & $1(25)$ & $2(50)$ & $1(25)$ \\
\hline $\mathrm{OSM}+\mathrm{CD}$ & 10 & $7(70)$ & $1(10)$ & $1(10)$ & $1(10)$ & $3(30)$ & $2(20)$ & $0(0)$ & $5(50)$ \\
\hline VEGFe & 6 & $3(50)$ & $1(17)$ & $1(17)$ & $1(17)$ & $1(17)$ & $0(0)$ & $0(0)$ & $5(83)$ \\
\hline
\end{tabular}

Pts, patients; CR, complete response; VGPR, very good partial response; PR, partial response; NR, no response; RT, radiotherapy; $\mathrm{CHT}$, chemotherapy; lg, immunoglobulin; OSM, osteosclerotic myeloma; CD, Castleman's disease; VEGFe, vascular endothelial growth factor elevation without growth lesion. 

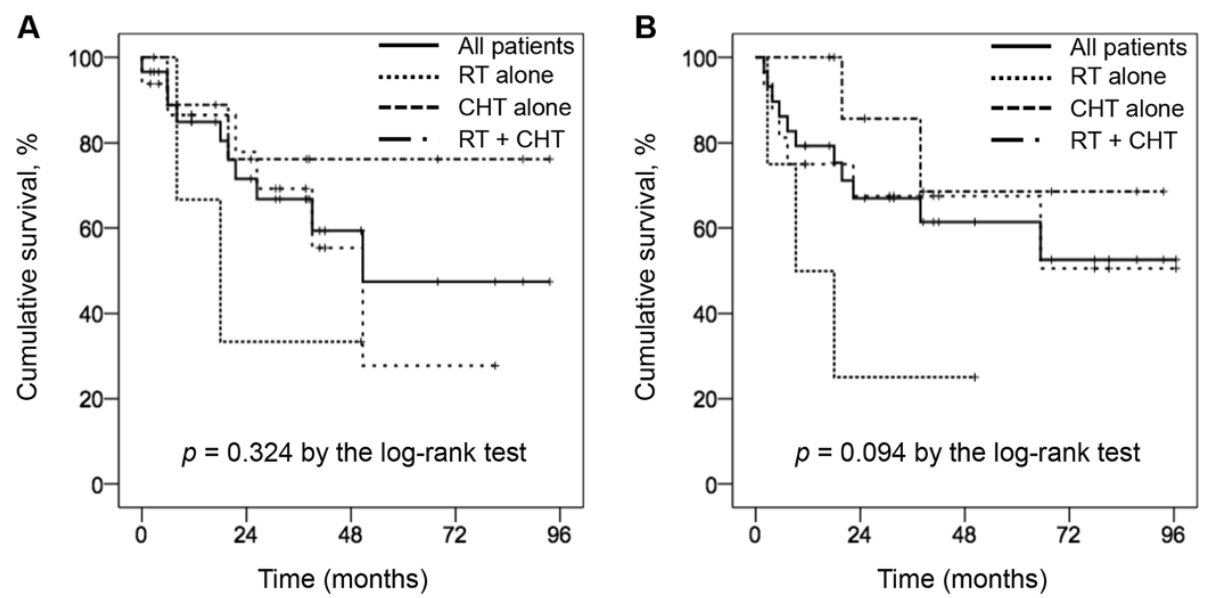

Figure 2 Kaplan-Meier plot of (A) progression-free survival and (B) overall survival for all patients $(n=33)$, and patients treated with radiotherapy alone $(n=4)$, chemotherapy alone $(n=16)$, and chemoradiotherapy $(n=9)$. RT, radiotherapy; CHT, chemotherapy.

appropriate, as in the case of solitary plasmacytoma $[12,22]$. In the present study, only three patients received radiation doses less than $40 \mathrm{~Gy}$, and among these three patients, one patient experienced disease progression. In addition, the two patients who did not respond to initial radiotherapy received 42 Gy and 50 Gy of radiotherapy. These doses were similar to those administered to the patients who responded to treatment, and were hence considered sufficient; therefore, the doses of radiation may not be responsible for the poor clinical responses, when radiation over $40 \mathrm{~Gy}$ was given.

Since disease multiplicity is associated with a higher risk of systemic involvement and a high burden of clonal plasma cells, it represents a very important factor to take into account for the decision of the treatment, especially, for patients with an underlying OSM. As a result, these patients are usually treated with chemotherapy, and the role of radiotherapy is thus uncertain in these patients.
In the present study, six patients with multiple lesions underwent radiotherapy, and this was found to have effectively improved the POEMS associated symptoms, although the hematologic response to radiotherapy was relatively poor in these patients.

Furthermore, in the present study, among the six patients presenting with VEGF elevation without gross lesions, five patients were treated with systemic chemotherapy, whereas the other one patient received systemic corticosteroid therapy and intravenous immunoglobulin. Interestingly, the treatment responses of these patients were poorer than those of the patients with osteosclerotic myeloma (Table 4). Moreover, the PFS and OS rates were found to be significantly inferior in these patients compared to those in patients with other subtypes of underlying disease (Table 5). A French study reported that six out of 25 POEMS patients did not have bone lesionlike monoclonal gammopathy of unknown significance

Table 5 Univariate prognostic factor analysis

\begin{tabular}{|c|c|c|c|c|c|}
\hline Factor & No. of case & 3-year PFS (\%) & $p$ value $^{*}$ & 3-year OS (\%) & $p$ value $^{*}$ \\
\hline Age $>50$ years (vs. $\leq 50$ years) & $13 / 20$ & $53.3 / 62.4$ & 0.931 & $56.4 / 66.0$ & 0.259 \\
\hline Radiotherapy (Y/N) & $13 / 20$ & $64.8 / 56.7$ & 0.310 & $66.6 / 59.4$ & 0.782 \\
\hline Chemotherapy $(\mathrm{Y} / \mathrm{N})$ & $25 / 8$ & $71.5 / 17.5$ & 0.007 & $74.1 / 18.2$ & 0.020 \\
\hline HD Chemotherapy with ABSCT (vs. SD chemotherapy) & $15 / 10$ & $80.8 / 58.3$ & 0.291 & $78.8 / 66.7$ & 0.253 \\
\hline IgG M-protein subtype (vs. other subtypes) & $17 / 16$ & $54.4 / 65.6$ & 0.719 & $61.1 / 65.8$ & 0.775 \\
\hline VEGF elevation without gross lesion (vs. other subtypes) & $6 / 27$ & 25.0/66.0 & 0.035 & $16.7 / 74.1$ & 0.008 \\
\hline BM plasma cells more than $5 \%$ (vs. $\leq 5 \%$ ) & $13 / 20$ & $61.4 / 59.5$ & 0.771 & $60.6 / 62.5$ & 0.821 \\
\hline The presence of abnormal clonal plasma cells in $\mathrm{BM}(\mathrm{Y} / \mathrm{N})$ & $5 / 28$ & $60.0 / 60.8$ & 0.249 & $80.0 / 60.4$ & 0.552 \\
\hline Extravascular volume overload except peripheral edema (Y/N) & $16 / 17$ & $49.2 / 70.0$ & 0.155 & $53.5 / 71.1$ & 0.212 \\
\hline Number of POEMS features $>7$ (vs. $\leq 7$ ) & $14 / 19$ & $46.4 / 67.7$ & 0.220 & $45.9 / 74.2$ & 0.127 \\
\hline Multiple bone lesions (vs. single bone lesion) & $12 / 11$ & $62.3 / 66.3$ & 0.742 & 77.9/70.7 & 0.906 \\
\hline
\end{tabular}

PFS, progression free survival; OS, overall survival; ABSCT, autologous peripheral blood stem cell transplantation; SD, standard dose; Ig, immunoglobulin; VEGF, vascular endothelial growth factor; BM, bone marrow.

"Log-rank test. 
[23], and clinical improvement was observed in only one patient among four patients with available data in that series [5]. The reason for the poor clinical outcomes in these patients is unclear, and previous studies have reported only a small number of POEMS patients presenting with VEGF elevation without gross lesions; therefore, further investigations regarding these patients is needed.

In the present study, the administration of chemotherapy significantly improved PFS and OS. Previous studies have demonstrated that melphalan-based chemotherapy protocols were able to achieve response rates over $40 \%$ $[4,6,15,24]$. Moreover, high-dose chemotherapy with PBSCT has also produced encouraging results, with a 5year PFS of $75 \%[11,13,25,26]$. Therefore, the selection of patients indicated for chemotherapy and the choice of chemotherapy regimen based on the patients' underlying clonal disease are important to improve outcomes.

The present study has some limitations including the retrospective nature and the relatively small sample size. Moreover, patients who did not undergo radiotherapy more frequently presented with adverse events such as ascites, pleural effusion, or pericardial effusion compared to patients treated with radiotherapy. Furthermore, among the 13 patients treated with radiotherapy, nine patients also underwent chemotherapy; and therefore, there is a possibility that the effects of radiotherapy may have been overestimated. However, despite these limitations, radiotherapy was found to produce good clinical responses in patients with a solitary lesion and clustered or limited multiple lesions, and radiotherapy may hence be effective as a definitive treatment in POEMS patients with localized OSM or as a palliative treatment to improve clinical symptoms in POEMS patients with clustered or limited multiple lesions.

\section{Conclusions}

We here have shown that radiotherapy produced good clinical and hematologic responses, especially in patients with an underlying OSM. Additionally, radiotherapy and chemotherapy appear to both be effective treatments for underlying plasma cell proliferative diseases. Furthermore, we also found that patients with POEMS syndrome presenting with VEGF elevation without gross lesions tend to have a poor prognosis. Further large-scale studies are needed in the future to improve the understanding of the underlying disease pathogenesis and to elucidate the appropriate management of this disease based on patient characteristics.

\section{Abbreviations}

OSM: Osteosclerotic myeloma; CD: Castleman's disease; VEGF: Vascular endothelial growth factor; CBC: Complete blood cell count; WBBS: Whole body bone scan; CT: Computed tomography; Ig: Immunoglobulin; VGPR: Very good partial response; PR: Partial response; NR: No response; PFS: Progression-free survival; OS: Overall survival.

\section{Competing interests}

The authors declare that they have no competing interests.

\section{Authors' contributions}

$J C$ designed the study. YGS and YSK collected the data. JC and YGS analyzed the data and wrote the paper. COS, YRK, JWC, and JSK discussed the results and implications and commented on the manuscript at all stages. All authors read and approved the final manuscript.

\section{Author details}

'Department of Radiation Oncology, Yonsei University College of Medicine, 50-1 Yonsei-ro, Seodaemun-gu, Seoul 120-752, South Korea. ${ }^{2}$ Division of Hematology, Department of Internal Medicine, Yonsei University College of Medicine, Seoul, South Korea.

Received: 13 August 2014 Accepted: 17 November 2014 Published online: 28 November 2014

\section{References}

1. Bardwick PA, Zvaifler NJ, Gill GN, Newman D, Greenway GD, Resnick DL: Plasma cell dyscrasia with polyneuropathy, organomegaly, endocrinopathy, $M$ protein, and skin changes: the POEMS syndrome. Report on two cases and a review of the literature. Med (Baltimore) 1980, 59:311-322.

2. Dispenzieri A: POEMS syndrome. Blood Rev 2007, 21:285-299.

3. Dispenzieri A: POEMS syndrome: 2014 update on diagnosis, risk-stratification, and management. Am J Hematol 2014, 89:213-223.

4. Nakanishi T, Sobue I, Toyokura Y, Nishitani H, Kuroiwa Y, Satoyoshi E, Tsubaki T, Igata A, Ozaki Y: The crow-fukase syndrome: a study of 102 cases in Japan. Neurology 1984, 34:712-720.

5. Soubrier MJ, Dubost JJ, Sauvezie BJ, French Study Group on POEMS Syndrome: POEMS syndrome: a study of 25 cases and a review of the literature. Am J Med 1994, 97:543-553.

6. Dispenzieri A, Kyle RA, Lacy MQ, Rajkumar SV, Therneau TM, Larson DR, Greipp PR, Witzig TE, Basu R, Suarez GA, Fonseca R, Lust JA, Gertz MA: POEMS syndrome: definitions and long-term outcome. Blood 2003, 101:2496-2506.

7. Dispenzieri A: POEMS syndrome: 2011 update on diagnosis, riskstratification, and management. Am J Hematol 2011, 86:591-601.

8. Li J, Tian Z, Zheng HY, Zhang W, Duan MH, Liu YT, Cao XX, Zhou DB: Pulmonary hypertension in POEMS syndrome. Haematologica 2013, 98:393-398.

9. Soubrier M, Dubost JJ, Serre AF, Ristori JM, Sauvezie B, Cathebras P, Piette JC, Chapman A, Authier FJ, Gherardi RK: Growth factors in POEMS syndrome: evidence for a marked increase in circulating vascular endothelial growth factor. Arthritis Rheum 1997, 40:786-787.

10. Dispenzieri A: How I treat POEMS syndrome. Blood 2012, 119:5650-5658.

11. D'Souza A, Lacy M, Gertz M, Kumar S, Buadi F, Hayman S, Dingli D, Zeldenrust S, Kyle R, Ansell S, Inwards D, Johnston P, Micallef I, Porrata L, Litzow M, Gastineau D, Hogan W, Dispenzieri A: Long-term outcomes after autologous stem cell transplantation for patients with POEMS syndrome (osteosclerotic myeloma): a single-center experience. Blood 2012, 120:56-62.

12. Humeniuk MS, Gertz MA, Lacy MQ, Kyle RA, Witzig TE, Kumar SK, Kapoor P, Lust JA, Hayman SR, Buadi FK, Rajkumar SV, Zeldenrust SR, Russell SJ, Dingli D, Lin Y, Leung N, Dispenzieri A: Outcomes of patients with POEMS syndrome treated initially with radiation. Blood 2013, 122:68-73.

13. Jaccard A, Royer B, Bordessoule D, Brouet JC, Fermand JP: High-dose therapy and autologous blood stem cell transplantation in POEMS syndrome. Blood 2002, 99:3057-3059.

14. Plata Bello J, Garcia-Marin V: POEMS syndrome (polyneuropathy, organomegaly, endocrinopathy, multiple myeloma and skin changes) with cranial vault plasmocytoma and the role of surgery in its management: a case report. J Med Case Rep 2013, 7:245.

15. Li J, Zhou DB, Huang Z, Jiao L, Duan MH, Zhang W, Zhao YQ, Shen T: Clinical characteristics and long-term outcome of patients with POEMS syndrome in China. Ann Hematol 2011, 90:819-826.

16. Dispenzieri A: POEMS syndrome: update on diagnosis, risk-stratification, and management. Am J Hematol 2012, 87:804-814.

17. Evison G, Evans KT: Bone sclerosis in multiple myeloma. Br J Radiol 1967, 40:81-89.

18. Morley JB, Schwieger AC: The relation between chronic polyneuropathy and osteosclerotic myeloma. J Neurol Neurosurg Psychiatry 1967, 30:432-442. 
19. Iwashita H, Ohnishi A, Asada M, Kanazawa Y, Kuroiwa Y: Polyneuropathy, skin hyperpigmentation, edema, and hypertrichosis in localized osteosclerotic myeloma. Neurology 1977, 27:675-681.

20. Davis LE, Drachman DB: Myeloma neuropathy. Successful treatment of two patients and review of cases. Arch Neurol 1972, 27:507-511.

21. Reitan JB, Pape E, Fossa SD, Julsrud OJ, Slettnes ON, Solheim OP. Osteosclerotic myeloma with polyneuropathy. Acta Med Scand 1980, 208:137-144.

22. Suh YG, Suh CO, Kim JS, Kim SJ, Pyun HO, Cho J: Radiotherapy for solitary plasmacytoma of bone and soft tissue: outcomes and prognostic factors. Ann Hematol 2012, 91:1785-1793.

23. International Myeloma Working G: Criteria for the classification of monoclonal gammopathies, multiple myeloma and related disorders: a report of the international myeloma working group. Br J Haematol 2003, 121:749-757.

24. Stewart PM, Mclntyre MA, Edwards CR: The endocrinopathy of POEMS syndrome. Scott Med J 1989, 34:520-522.

25. Ganti AK, Pipinos I, Culcea E, Armitage JO, Tarantolo S: Successful hematopoietic stem-cell transplantation in multicentric Castleman disease complicated by POEMS syndrome. Am J Hematol 2005, 79:206-210.

26. Wiesmann A, Weissert R, Kanz L, Einsele H: Long-term follow-up on a patient with incomplete POEMS syndrome undergoing high-dose therapy and autologous blood stem cell transplantation. Blood 2002, 100:2679-2680.

\section{Submit your next manuscript to BioMed Central and take full advantage of:}

- Convenient online submission

- Thorough peer review

- No space constraints or color figure charges

- Immediate publication on acceptance

- Inclusion in PubMed, CAS, Scopus and Google Scholar

- Research which is freely available for redistribution 